\title{
FLOW NEAR AN ICE DIVIDE: ANALYSIS PROBLEMS AND DATA REQUIREMENTS
}

\author{
by \\ E.D. Waddington \\ (Geophysics Program AK-50, University of Washington, Seattle, WA 98195, U.S.A.) \\ and \\ D.A. Fisher and R.M. Koerner \\ (Polar Continental Shelf Project, Energy, Mines and Resources Canada, 880 Wellington St., \\ Ottawa, Ontario K1A OE4, Canada) \\ and \\ W.S.B. Paterson
}

(Paterson Geophysics Inc., Box 303, Heriot Bay, B.C. VOP 1HO, Canada)

\begin{abstract}
Climate studies using ice cores require knowledge of the ice deformation at a detailed level, obtainable only by integrated surveying and flow modelling. Field programs should consider model abilities and requirements at the planning stage. Strain and topographic surveys should enclose the flowlines to all boreholes and extend beyond. Only then is it possible to (1) calculate representative slopes at the drill sites and (2) use simple boundary conditions at locations where they do not affect the calculated flow near the holes. Mass conservation models, which may include a parameterized velocity field, estimate the imbalance between integrated accumulation and ice discharge. Momentum conservation models find the actual velocity field, and can reveal a more detailed flow history, but require detailed survey information for boundary conditions. A mass conservation model suggested that flow near core sites at Agassiz Ice Cap, Ellesmere Island, had been steady for more than 3000 years; however, a momentum conservation model showed that either the present transverse strain rate is much smaller than required by the mass conservation model, or the ice is much stiffer than accepted values. It also revealed transients in the flow and microclimate of which the impact on the derived climate still needs to be assessed by integrated modelling and surveying.
\end{abstract}

\section{INTRODUCTION}

Coreholes for climate studies have created a need for detailed information about flow patterns near ice divides. Workers in the field need to know whether an ice divide is thinning, thickening, or migrating. When interpreting gas content and stable isotope profiles to derive paleoclimate and remove elevation effects, they need to know the age of the ice and the origin point in three dimensions for each particle path to the cores. Total strain calculations are needed to assess mass-balance history from annual layering, and to study fabric and ice rheology. The influence of a rough bed on the time scale for deep ice is a complicated problem, requiring modelling.

Deformation rate can be measured only at the ice surface and in boreholes. Flow modelling is necessary to derive the pattern elsewhere. There are two types of flow model in general use for flow in longitudinal section.

\section{FLOW MODELS}

Mass conservation (continuity) models balance integrated accumulation against ice discharge to calculate average flow speeds or rates of thickness change. Ice rheology and dynamics are parameterized (laminar flow models) or ignored (balance velocity models). These models require data on surface and bed topography, flowband width, and mass balance. The advantage of these models is the simplicity of the boundary conditions, i.e. zero ice flux at the divide. The disadvantage is a frequent inability to provide the detailed information required for corehole studies near divides, where the momentum equations cannot easily be parameterized and depth-averaged properties are not useful.

A second type of flow model uses the finite element technique to solve the combined conservation equations for mass, momentum, and (sometimes) energy. These momentum conservation models are becoming more common (Hooke and others, 1979; Raymond, 1983; Paterson and Waddington, 1984; Budd and Rowden-Rich, 1984). They incorporate Glen's flow law (e.g. Paterson, 1981, p.39) and require data on bed and surface topography, flow law parameters, and surface temperatures. Paterson and Waddington (1984) also incorporated horizontal strain, transverse to the flow direction. The advantage of these models is the detailed solution they provide for the velocity and stress fields. If steady state can be assumed, they also provide particle paths and time scales. The disadvantage is the detailed boundary conditions they require. Stress or velocity boundary conditions must be specified on all ice surfaces bounding the solution region. If we consider a two-dimensional vertical section along a flow band (Figure 1), the natural boundary conditions are (1) free upper surface and (2) specified velocity (e.g. zero) along the base; however, bed and surface geometry are seldom known to the margin of the ice cap, so conditions must be imposed on non-physical boundaries such as AB. There are three types. (1) When bedrock and surface crests coincide (CD), it may be possible to approximate a boundary there with a symmetry condition, i.e. vanishing shear stress and horizontal velocity. This is not appropriate for the more general case IJ. (2) If the velocity is measured in a borehole (EF), the borehole can be used as a specified velocity boundary. (3) Of ten it is preferable to leave the borehole deformation rate free to be a part of the solution which can be checked against velocity measurements, or used to provide a velocity prof:le and time scale for a hole without measurements. Boundary conditions, derived from simple assumptions (e.g. laminar flow), can be applied at distant boundaries $\mathrm{AB}$ and $\mathrm{GH}$, where the detailed form of the boundary condition does not affect the flow to the borehole. Paterson and Waddington (1984) and Raymond (1983) used this approach. 


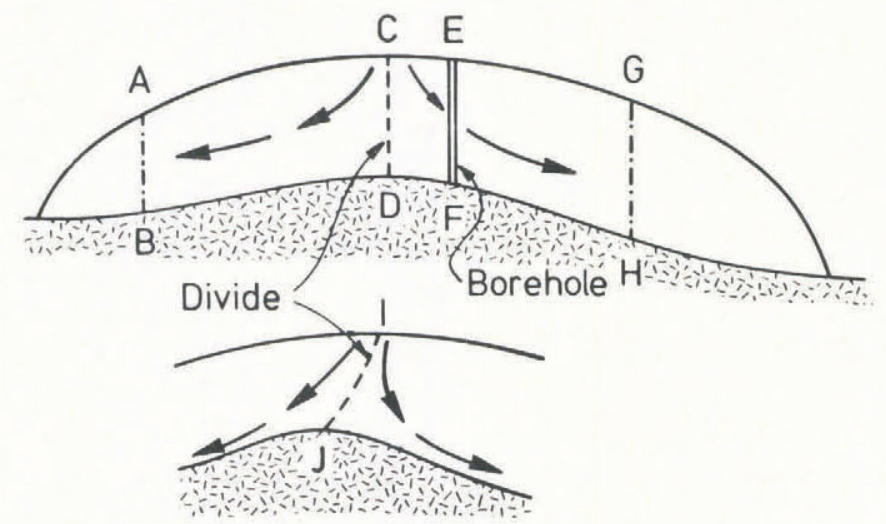

Fig.1. Boundary types for momentum conservation models. Upper surface is free. Zero velocity is specified at a cold bed. When surface and bed are not known over the full ice mass, internal boundaries must be used. Some ice divides (CD) can be approximated with a symmetry condition. Others (IJ) cannot. Velocity measured in a borehole (EF) can be a boundary condition. Laminar flow boundary conditions can be used at $\mathrm{AB}$ and $\mathrm{GH}$ far from the boreholes.

Because these models need detailed boundary conditions which are unknown in the past, time-dependent flow calculations may be difficult to interpret.

\section{DATA REQUIREMENTS}

While the momentum conservation models provide good velocity solutions near boreholes, they also require more constraints and boundary conditions. These can be provided only by more complete and more accurate survey data Anticipating that detailed flow modelling will be required to maximize the analysis benefits from an expensive corehole, field programs should be planned with the model requirements in mind. Bader (1962) gave a succinct, but comprehensive description of the data requirements for a deep core program. We summarize important points. Field programs should measure, at the borehole:

1) borehole stable isotopes $\left(8^{18} \mathrm{O}\right)$ and gas content, for paleoclimate

2) borehole temperature, to test isotopically-derived paleotemperature history

3) borehole tilting (by inclinometry), closure (by caliper measurements), and shortening (by differential motion of diameter irregularities), to find ice velocity and flow law.

A surface data net, completely surrounding flowlines to the holes, should measure:

4) Surface topography (levelling, triangulation, photogrammetry, or satellite altimetry)

5 ) bed topography (by radio echo-sounding)

6) regional mass balance distribution (by stake network, or pits)

7) regional $15 \mathrm{~m}$ temperature, to assess microclimate variability and impact on paleoclimate interpretation.

8) regional, stable isotope distribution in recent snow, to assess temperature- $\delta^{18} \mathrm{O}$ relation

9) surface strain rate (triangulation, trilateration, photogrammetry, repeated satellite altimetry and positioning), to determine flow divide, flowline location, and surface velocity.

Not all of these are routine. In particular, 9) is critical for flow modelling. It is very important that the regional survey network surrounds the flowlines from the ice divide to all boreholes, to determine transverse strain rates, a priori, and to verify calculated surface deformation and velocity at the holes, a posteriori.

The survey net should also extend well beyond the borehole and across the upstream ice divide. There are two reasons for this. First, the ice thickness gradient and surface slope are represented best by average values over scale lengths comparable to the ice depth or longer. To avoid loss of data quality at the borehole site, itself, and at the divide, observations must extend at least several ice depths beyond.

Secondly, in order to calculate the flow at the borehole, distant, simple boundary conditions must be used (GH in Figure 1). Based on results in Raymond (1983), we estimate that surface and bed topography, transverse surface strain rate, and mass balance should be measured at least ten ice depths beyond the borehole or to a region where the flow is truly laminar. Then we can be confident that the imposed condition, which is only approximate, does not adversely influence the flow to the boreholes.

\section{AGASSIZ ICE CAP SITE}

We used both types of model to estimate flow at a borehole site at Agassiz Ice Cap, Ellesmere Island. The site (Figure 2) was described by Fisher and others (1983). Three coreholes, drilled in 1977, 1979, and 1984, separated by

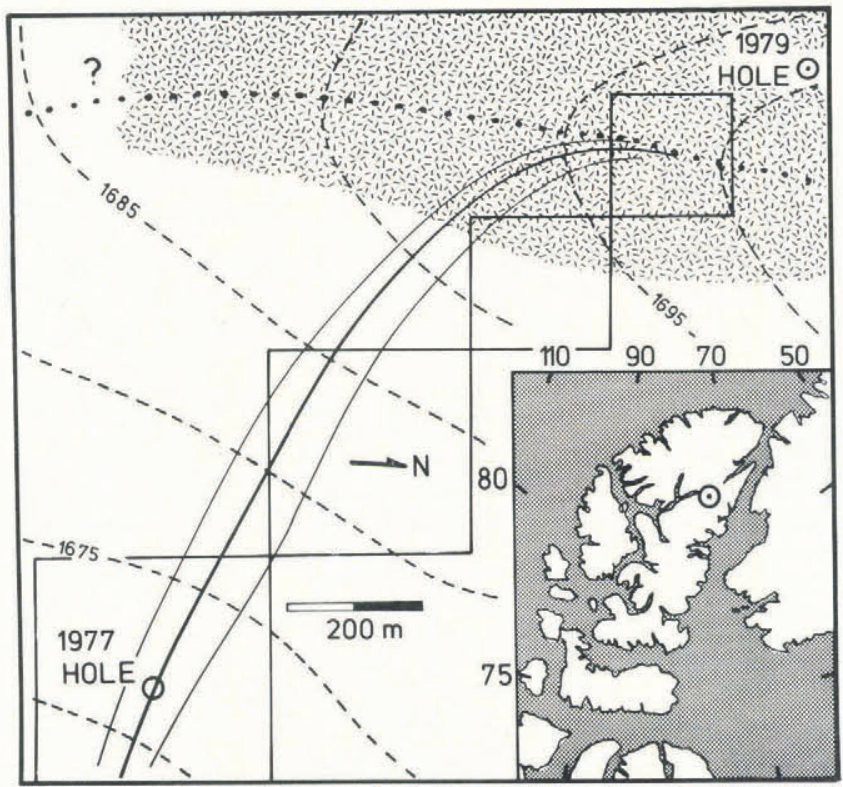

Fig.2. Smoothed surface topography at $5 \mathrm{~m}$ intervals in the vicinity of the boreholes at Agassiz Ice Cap, derived by contouring levelling data on a $200 \mathrm{~m}$ grid. The heavy solid line is the flowline through the 1977 hole. The two nearby flowlines define a flowband. Scouring is thought to occur in the shaded area along the divide (dotted line). Diamonds show part of strain net. Inset: location map of Ellesmere Island. The circle marks the drill site.

distances of about $1 \mathrm{~km}$, reached bedrock at and near a local ice divide over a bedrock ridge. The ice depth at the ridge is about $140 \mathrm{~m}$. It increases to $338 \mathrm{~m}$ at the 1977 hole. The surface slope along the flowline is nearly constant at $2^{\circ}$. The bed slope increases smoothly to $18^{\circ}$ at the hole. Surface temperatures average about $-24^{\circ} \mathrm{C}$ and the base is frozen. The mass balance (Figure 3a) was measured over four years, on a stake network crossing the crest. Fisher and others attributed the low balance near the divide to microclimate; enhanced winter wind scouring removes snow there (Figure 2).

Inclinometer measurements in the hole, in 1977 and 1979 , by a geophysical contractor, gave a surface velocity of $0.70 \mathrm{~m} \mathrm{a}^{-1}$ and a depth-averaged velocity of $0.62 \mathrm{~m} \mathrm{a}^{-1}$, with a standard deviation of about $8 \%$, because the bottom ten meters of the hole were apparently inaccessible. A recent reassessment has raised the possibility of systematic depth error in the contracted survey. If the inclinometer reached the bed, the surface velocity could be as low as $0.50 \mathrm{~m} \mathrm{a}^{-1}$, with a depth-averaged velocity of $0.45 \mathrm{~m} \mathrm{a}^{-1}$.

The surface flow direction differed by only one degree from the direction of steepest surface slope, averaged over $400 \mathrm{~m}$ (slightly greater than one ice depth). Flow azimuth varied by more than this amount with depth. Therefore, we used the steepest gradient of the smoothed surface (Figure 
1) to define the flowline through the borehole. A line of strain diamonds (Figure 2), with sides equal to the local ice depth, crossed the divide. Since it did not follow the flowline, we made most use of the diamond at the 1977 hole.

An absolute time scale for the 1977 core, given in Fisher and others (1983), was established by measuring annual layers. Based on a comparison of the isotopic records in the boreholes, Fisher and others predicted that the flow time from the edge of the scoured zone to the borehole was about 3000 years.

Because of scouring, the isotopic records in the cores from near the ridge are weighted towards summer temperatures. Only the 1977 core can give a record of mean annual temperature, yet even it is affected by scour, because the deep ice originated in the scour zone. To correct for the scouring and thus derive a true climatic signal from this site, we must show that the microclimate (scour zone) and ice-cap flow have been steady for about 5000 years, or else derive their variations. We used two models to estimate properties of the flow, with disparate results.

\section{MASS CONSERVATION FLOW MODELS FOR AGASSIZ ICE CAP}

Fisher and others (1983) reported a balance velocity calculation, assuming plane strain, using distance $x$ measured along the flowline in Figure 2, mass balance $b(x)$ in Figure $3 a$, and ice depth $h(x)$, from radio echo-sounding. The balance velocity at the borehole was within the standard deviation of the original inclinometer result. The travel time, from the edge of the scour zone to the hole, was 1500 years, only half the time given by the isotope records, suggesting a history of variable ice thickness, flow rate, or scouring.

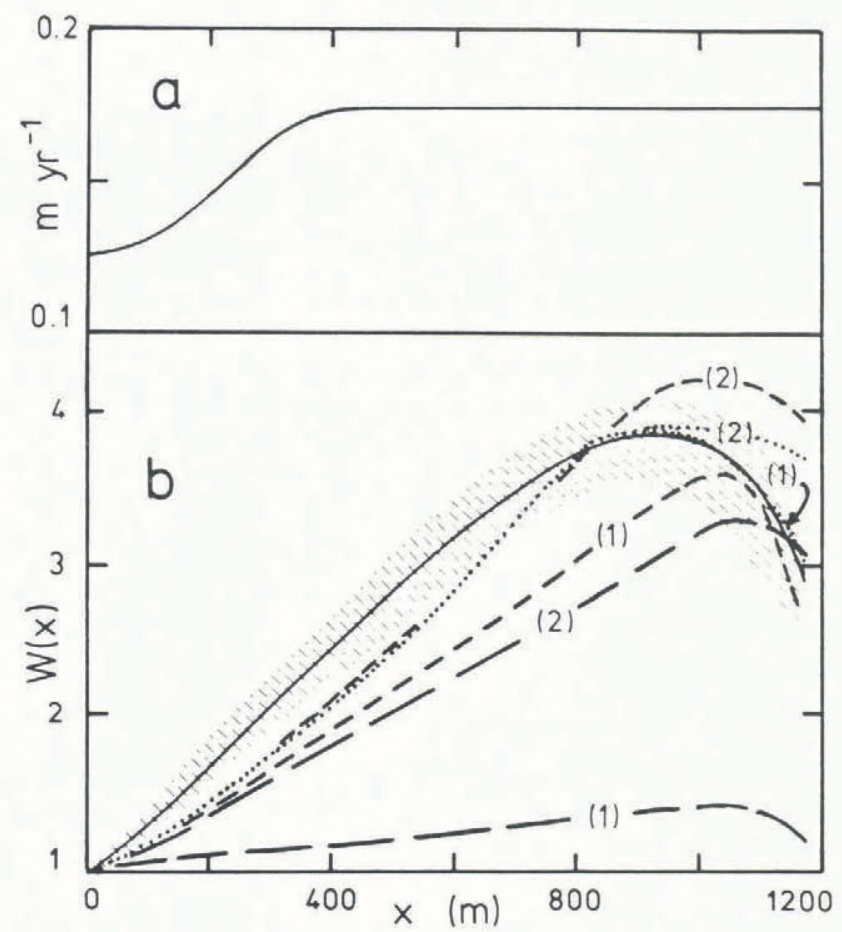

Fig.3. (a). Mass balance in ice-equivalent measured over four years, at a stake network crossing the divide. $x$ is measured along the flowline in Figure 2. (b). Flowband width $\mathrm{W}(\mathrm{x})$. Solid curve is derived from smoothed surface contours. Shaded area is error estimate. For all curves labelled (1), depth-averaged velocity at the hole was 0.62 $\mathrm{m} \mathrm{a}^{-1}$; for curves (2), $0.45 \mathrm{~m} \mathrm{a}^{-1}$. Dotted curves are continuity models. Dashed curves are momentum conservation models. Short dashes show best match to continuity models and surface slope data. The ice is very stiff. Long dashes show models with ice softness optimized. (2) is still too stiff.
We have improved their balance flux calculation by including transverse strain rates. We found the location of two flowlines near the 1977 hole flowline, by assuming that flow followed the steepest slope on the smoothed contour map (Figure 2). The distance $\mathrm{W}(\mathrm{x})$ (solid curve in Figure $3 b)$, between the outer flowlines, defined a flowband. The shaded area estimates the uncertainty in $W(x)$. We ignored azimuth variations of flow with depth. The balance velocity $\bar{u}(x)$ was then

$$
\bar{u}(x)=\frac{1}{W(x) h(x)} \int_{0}^{x} W\left(x^{\prime}\right) b\left(x^{\prime}\right) d x^{\prime}
$$

Using the flowbands shown by dotted lines in Figure $3 \mathrm{~b}$, we obtained flow times near 2500 years, from the scour zone edge to the borehole, in reasonable agreement with the value from the isotope study. For all curves labelled (1) and (2) in Figure $3 \mathrm{~b}$, the depth-averaged velocities at the hole were $0.62 \mathrm{~m} \mathrm{a}^{-1}$ and $0.45 \mathrm{~m} \mathrm{a}^{-1}$ respectively. Regardless of which interpretation of the inclinometry is preferred, this improved mass-balance calculation suggested that: (1) the ice cap profile and flow had been steady for at least 3000 years, (2) scouring had existed for thousands of years, and (3) the location of the scouring zone had not changed.

\section{MOMENTUM CONSERVATION MODEL FOR AGASSIZ ICE CAP}

As a further test, we then asked whether cold glacier ice has the required rheological properties to sustain a steady flow in the geometry of the kinematic model. The details of the momentum conservation model will be reported elsewhere. The model required the measured surface and bed heights, the width $W(x)$ of the flowband, the flow law constants $A$ and $n=3$, and the temperature field in the ice. The boundary conditions were (1) free upper surface, (2) motionless basal ice, (3) measured velocity in the 1977 borehole, and (4) symmetric flow divide. The model produces the velocity and stress fields. It also produces particle paths, if we assume the flow is steady. Even in non-steady flow (except for surging glaciers), the submergence velocity is close to the mass-balance rate. For each borehole velocity profile, we adjusted one of the two, least well known, input quantities, the flow law softness $A_{0}$, or the flowband width $\mathrm{W}(\mathrm{x})$, until the calculated submergence velocity approximated the measured mass balance.

First, we tried models with flowbands $\mathrm{W}(\mathrm{x})$ similar to those from the continuity models. Flowbands, shown by short dashed curves in Figure $3 \mathrm{~b}$, satisfied the submergence velocity condition; however, we were forced to make the ice unreasonably stiff. For curve (1) (average velocity 0.62 $\mathrm{m} \mathrm{a}^{-1}$ at the hole), $A_{0}$ was equal to 0.15 of the value recommended by Paterson (1981, p 39), 0.07 of the value found most suitable for a similar ice cap, at Devon Island, by Paterson and Waddington (1984), and 0.007 of the value Paterson (1983) found for Holocene ice at Byrd and Camp Century. In addition, the horizontal strain rates at the hole, averaged over the dimensions of the strain diamond there, were five times bigger than the measured values. For curve (2) $\left(0.45 \mathrm{~m} \mathrm{a}^{-1}\right.$ at the hole), the required $A_{0}$ was even smaller by $36 \%$. However, the averaged surface strain rates agreed with the observed values.

Next, we tried to keep $A_{\circ}$ near the recommended value (Paterson, 1981, p.39), while allowing $\mathrm{W}(\mathrm{x})$ to vary. The flowbands for the best results are shown by long dashes in Figure $3 \mathrm{~b}$. Curve (1) had a softness $A$ of $4.0 \times 10^{-16} \mathrm{kPa}^{-3}$ $\mathrm{s}^{-1}$ at $-20^{\circ} \mathrm{C}$. This value was best for a model of a similar ice cap at Devon Island (Paterson and Waddington, 1984) and is within a factor of 2.2 of the value recommended by Paterson (1981). With $0.45 \mathrm{~m} \mathrm{a}^{-1}$ at the hole, the flowband (curve (2)) agreed better with the slope-derived values, but the sof test possible ice was still too hard. A。 was less than 0.18 of Paterson's (1981) value and 0.09 of the Devon Island Ice Cap value. For both models, the averaged surface strain rates at the hole agreed with measurements.

Assuming steady state, the flow time, from the edge of the scour zone to the hole, was 2200 to 2300 years for all 
models except the narrowest flowband (long dashed line (2)), which gave 1500 years. These times are significantly less than the 3000 years given by the isotopic profile. In addition, steady state particle paths in all the momentum conservation models gave essentially identical time scales, that placed ice of a given age too deep in the core, when compared to the measured time scale.

These momentum conservation calculations question the conclusions of steady flow and microclimate, reached through the mass conservation calculation, although the detailed history is still obscured by data limitations. In the past, the ice cap flow may have been slower, or the scour zone may have been narrower. The transverse strain rates now may be only $10 \%$ of the long term average. The surface slopes, which control the flow direction, are only a few degrees, and may change due to variability in the wind scouring. The ice may be much stiffer than the accepted value of A. Inclinometry cannot give a reliable independent estimate of $A_{o}$, because the stress field near the hole is complicated and unknown. We are addressing these questions further, with sensitivity tests and paleo-precipitation calculations that will be reported elsewhere.

\section{CONCLUSIONS}

Momentum conservation calculations for ice corehole sites yield flow solutions with detail superior to results of continuity calculations, but are limited by the survey data used as boundary conditions. Field measurements should be planned to include and meet model requirements. In particular, strain rate observations should enclose the flowlines to the boreholes and extend beyond, so that the velocity at the surface and in the hole can be checked.

Mass conservation models alone should not be used to test for steady state. Comparison of good survey data with momentum conservation models can detect transient behaviour at a subtle level. A continuity model for flow near boreholes at Agassiz Ice Cap implied that flow and microclimate had been steady for thousands of years. A more detailed momentum conservation model showed that, either the present flowband differs significantly from the pattern in the mass conservation model, or the ice is much stiffer than the best accepted values. Recent transient behaviour in the flow or microclimate was also found Further interpretation is limited now by insufficient field data. The influence of these transients on the derived climate signal still needs to be assessed with an integrated survey and model study. The existing strain net did not totally enclose the flow line, and the bed and surface topography are poorly known downstream from the hole. A larger strain net is needed to help us better estimate the flowband, to independently determine the surface velocity, to separate microclimate from ice thickness changes, and to make scouring corrections to the isotopic record.

\section{ACKNOWLEDGEMENTS}

This research was carried out under DSS contract No. 20SU23239-1-0041 to the University of British Columbia from Polar Continental Shelf Project.

\section{REFERENCES}

Bader H 1962 Scope, problems and potential value of deep core drilling in ice sheets. CRREL Special Report 58

Budd W F, Rowden-Rich R J M 1985 Finite element analysis of two-dimensional longitudinal section flow on Law Dome. ANARE Research Notes 28: 153-161

Fisher D A, Koerner R M, Paterson W S B, Dansgaard W, Gundestrup N, Reeh N 1983 Effect of wind scouring on climatic records from ice core oxygen-isotope profiles. Nature 301 (5897): 205-209

Hooke R L, Raymond C F, Hotchkiss R L, Gustafson R J 1979 Calculations of velocity and temperature in a polar glacier using the finite-element method. Journal of Glaciology 24(90): 131-146

Paterson W S B 1981 The physics of glaciers. Second edition. Oxford etc, Pergamon Press

Paterson W S B 1983 Deformation within polar ice sheets: an analysis of the Byrd Station and Camp Century borehole tilting measurements. Cold Regions Science and Technology 8(2): 165-179
Paterson W S B, Waddington E D 1984 Past precipitation rates derived from ice core measurements: methods and data analysis. Reviews of Geophysics and Space Physics 22: $123-130$

Raymond C F 1983 Deformation in the vicinity of ice divides. Journal of Glaciology 29(103): 357-373 